\title{
The Multi-Level Classroom or The One Room Little Red Schoolhouse Revisited
}

Robert Courchêne

ESL classes are often composed of students from different language groups who are at different levels of language proficiency. We need to adapt traditional methods and settings to accommodate this reality if we wish to provide our students with rich language input. This article pro- poses a listening activity: the use of multilevel tasks drawing from a common text using the resources of the language lab. As well as offering a rationale and guide to the use of the language lab, it features practical suggestions for structuring exercises and examples of exercise types.

For teachers at all levels of education but, in particular, at the elementary and secondary levels, the multi-level classroom is an all too common reality. In large urban centres, the problem is further compounded by the fact that such classes are multi-cultural and often include students with varying levels of formal education. Experienced teachers realize that there are no simple solutions to such problems; there are only more or less effective partial solutions.

I would like to propose one possible approach to the problem that involves the use of language laboratories. With some adaptation it could also be used with listening centres in the classroom. A historical perspective of the language lab and a discussion of theoretical issues precede the presentation of this approach.

\section{THE LANGUAGE LABORATORY}

In the history of any civilization it is very common for a certain type of art or music or dance to become associated with a fixed historical period. In teaching, as well, certain techniques and modes of technology have also become closely associated with specific teaching methods. The language laboratory was introduced in conjunction with the audio-lingual and audio-visual methods that were developed in the 1940's and 1950's. The language lab was considered an integral part of the program. It was the ideally suited technological apparatus to help students master the set of language habits. Many methods were accompanied by drill books 
intended to provide the student with practice for all the structures; e.g., Dialogue Canada, Beginning English Language Lessons, Foreign Service Institute French. The language lab was tied to pattern practice. Teachers took their students there to drill the structures that had previously been presented in class. Irrespective of the pedagogical validity of such exercises, it is evident that the use of the language lab in language teaching and learning was narrowly defined.

With the partial demise of the audio-lingual and audio-visual methods of the 1960's, the language lab often became a white elephant, an embarrassment. As a result of this demise, many language labs fell into disuse for a period of about 10 years. Since the early 1970's, however, theoreticians and practitioners alike have been rediscovering the importance of listening. They have realized that the language lab helps students learn how to listen, that the language lab can be used to individualize student instruction and that the language lab can be used to teach oral and written expression without ever having the students perform a single pattern drill.

It is within this perspective that I would like to propose the use of the language lab as a possible solution to the teaching of the multi-level class. The theory on which this approach is based draws on the work of Krashen (1981, 1982).

\section{THEORETICAL FRAMEWORK: KRASHEN'S SECOND LANGUAGE ACQUISITION THEORY}

The main points of Krashen's theory are now briefly summarized and their relevance for the language lab discussed.

\section{Acquisition vs Learning}

Krashen uses these two terms in a scientific way. Acquisition is a process similar to how children develop ability in their first language. It is unconscious; it explains our fluency in the language. It is the type of knowledge that enables a native speaker to say that something "feels or sounds right." Learning refers to competence related to knowing about a language; it is the conscious knowledge we have of the rules. This knowledge is not responsible for our fluency for we can only use it if we have time, if we are focussing on form, and if we know the rule (the Monitor hypothesis). In normal conversations these conditions can rarely be met; we are more interested in the message than in the form.

For acquisition to take place in and outside of the classroom, certain conditions have to be met. 


\section{Comprehensible Input}

What the language student hears must be comprehensible and contain structures that are just beyond the student's competence. Most teachers and mothers (caretakers) automatically adjust their speech so that it contains elements just beyond what the student can produce but can still understand.

\section{Affective Filter}

If acquisition is going to take place, the affective filter must be low. The student must not be under undue stress to perform. Asking students to perform without competence induces stress. Under such conditions, students are less receptive, and their motivation to learn decreases.

\section{Interesting and Relevant Subject Matter}

The subject matter of the language class must be of some interest to the students. This is one of the most difficult conditions to meet. Students who come to our language classes frequently have a wide variety of expectations and needs. According to Krashen, input that is interesting and relevant focusses the acquirer on the message and not the form. Students thus engaged forget they are hearing another language.

\section{Not Grammatically Sequenced}

The input the $\mathrm{L}_{2}$ student is exposed to should not be grammatically sequenced. It should not be based on a structure-a-day approach. Natural input which is understood will expose the $\mathrm{L}_{2}$ acquirer to all the structures in sufficient quantities. As well, structures will be constantly recycled; students will not have to worry about having missed the presentation of a particular point of grammar. This does not mean, on the other hand, that we should not teach grammar formally (Krashen, 1982).

\section{Sufficient Quantity}

To acquire a language, we need a large quantity of comprehensible input. In the average ESL classroom input is often lacking in both quantity and variety. This is particularly the case if large blocks of time are spent on grammar-oriented activities.

\section{Delayed Speaking}

Ideally, students should not be asked to perform until they have acquired the necessary competence. Research (Asher, 1977; Gary, 1975; 
Postovsky, 1974) has demonstrated that $\mathrm{L}_{2}$ students who were not required to speak until they were ready did as well or better in all four skills than those who were required to perform from the beginning. Not asking students to perform also lowers the affective filter; consequently, they are less afraid of possible embarrassment due to error. In addition, delayed speaking usually results in a better mastery of the phonological system.

I believe that the conditions necessary for acquisition can be met for the multi-level class in a well-designed language lab program. All the students can get sufficient quantities of non-grammatically sequenced, interesting comprehensible input in the language lab. They can work on this comprehensible input at their own speed and do not have to produce orally. Such conditions should sustain their motivation and reduce tension and apprehension. How, you may wonder, is it possible to meet all of these conditions with a multi-level class while using only one program at a time? I would like to suggest that it is by adopting a progression based on the difficulty of the learning task to be completed rather than a strict grammatical progression. This has certain advantages. First, it enables the students to work with relevant "authentic" texts rather than a contrived text prepared to present a specific grammatical point. As all texts are only authentic for the situation for which they are prepared, even our most authentic texts will have a degree of inauthenticity. Second, it enables the teacher to use a single text at a level that approximates their $\mathrm{L}_{2}$ ability. Third, since students are doing something challenging, yet comprehensible, they are not unnecessarily tense.

To provide you with a guide of the type of levels of task difficulty that I am referring to, I have included a copy of the 1981 Royal Society of Arts (RSA) band levels for testing aural comprehension (see Appendix A). Before beginning to prepare exercises, I match the students in the class with the different levels specified by the RSA. I then proceed to construct exercises that meet the RSA criteria. At the most basic level, I ask questions that would exact global understanding of short texts with no topic changes. The elementary student would be allowed, of course, to listen to the text as frequently as would be necessary to do the exercises. The band levels specified by the RSA can be supplemented by different taxonomies of aural comprehension questions such as those suggested by Rivers and Temperley (1978). The main point here is that the same text can serve as a basis for many different types of questions with varying levels of difficulty.

Before turning to some practical examples, a word of caution is in order. Questions should "reveal themselves"; they should be natural outgrowths of a given text. I never force a text to "cough up" a requisite 
number of questions. As well, some texts lend themselves better to one type of question than another.

\section{PRACTICAL APPLICATIONS}

This section will begin with a few remarks about the sources of, and the criteria for, the selection of texts. This will be followed by guidelines for the preparation of exercises and the presentation of sample texts and exercises.

\section{Authentic Texts: Selection and Sources}

One of the buzz words of language teaching today is "authentic." In many contexts it is tacked on as an "in-adjective" to give a special aura to the task at hand. For our purposes, authentic texts must meet three criteria:

1. Authentic in that they are samples of normal interactive language characterized by false starts, lapses, variations in register, etc.;

2. Authentic in that the text was meant to be heard and not read or written;

3. Authentic in what we ask the $\mathrm{L}_{2}$ student to do with the text; e.g., the type of activity that one would expect a native speaker to be able to perform after hearing the text, and the type of activity that would be appropriate to the text heard.

Many sources for authentic texts (as defined above) exist in the community at large. For example, we can use selections from the radio, television and films. We can also gather real samples using a tape recorder or a telephone pick-up. To be of use, the texts should be comprehensible, clear (unless we want to use background noise to add to the difficulty) and of interest and relevance to the students.

\section{Preparation of Exercises}

When I set about preparing texts for multi-level classrooms, I use the framework presented in Figure 1. The weaker student works on material within the text itself and is provided with a support network in the form of vocabulary, questions, outlines, or portions of the text. As the task demanded of the student becomes more difficult, less support is provided in the form specified above and the student is more frequently asked to use the spoken text as a basis for going beyond it; i.e., making inferences, predictions, etc. This is shown schematically in Figure 2. The bands from 
the RSA have been integrated into the schema.

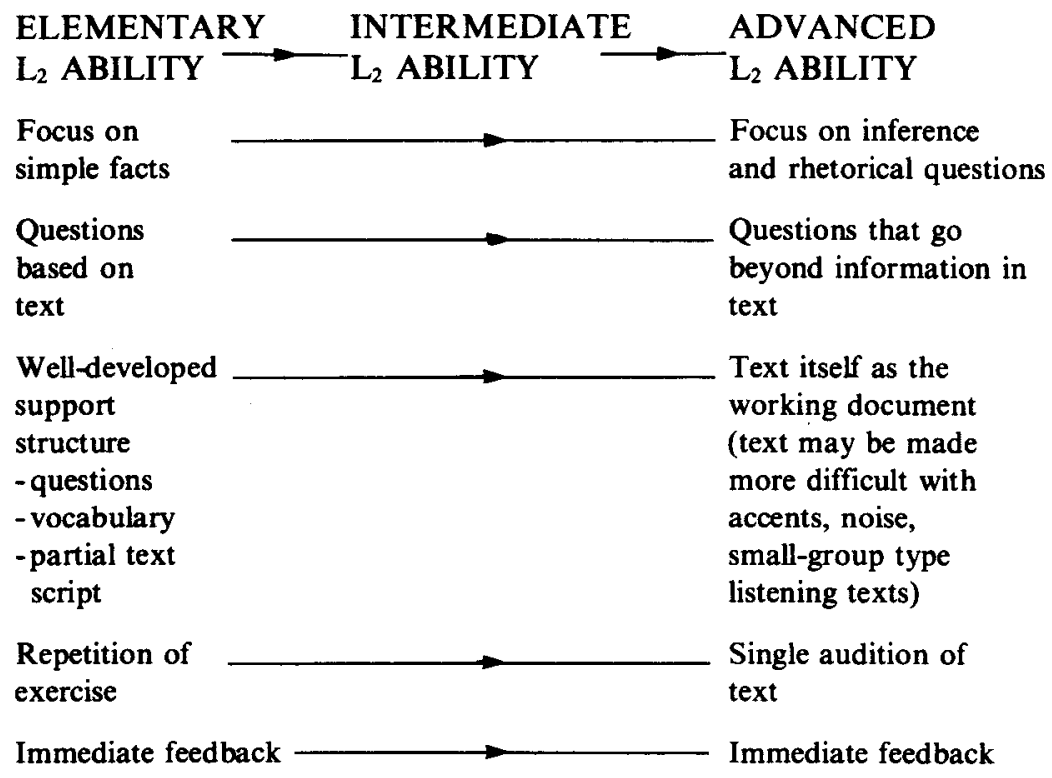

Figure 1. Framework for preparing aural comprehension questions.

\begin{tabular}{|c|c|c|c|}
\hline $\begin{array}{c}\text { TASK } \\
\text { PROGRESSION }\end{array}$ & $\begin{array}{c}\text { SUPPORT } \\
\text { STRUCTURES }\end{array}$ & FOCUS & $\begin{array}{c}\text { RSA } \\
\text { BANDS }\end{array}$ \\
\hline$\downarrow_{\text {Complex }}$ & $\left.\right|_{\text {Absent }} ^{\text {Elaborate }}$ & 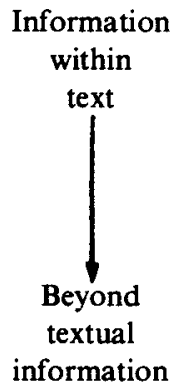 & Intermediate \\
\hline
\end{tabular}

Figure 2. Progression in aural comprehension exercises.

In Figure 2, the arrow in the box entitled "Support Structures" is bi-directional for a special reason. It is possible to make a simple text more 
difficult by removing some or all of the support structures (i.e., vocabulary, explanation of questions); on the other hand, it is possible to make a difficult text more comprehensible by increasing the support structures. It is up to the teacher to vary the support structures according to the $\mathrm{L}_{2}$ ability of the students. If we distribute our students in the multi-level class along the elementary-to-advanced continuum (see Figure 1), we can then begin to prepare exercises that will be suitable for each group's $L_{2}$ ability.

Before presenting actual texts and exercises, I would like to make one remark concerning grammar. To say that the progression of exercises is based on the difficulty of the task to be performed does not mean that one of the criteria used in determining difficulty is not grammar. Rather, it means that grammar is not the only criterion used as it frequently was in the past. If we use authentic texts, this will almost of necessity guarantee that it can never be the sole criterion of task difficulty.

The methodology for preparing exercises for a multi-level class will be illustrated using a text I recorded for one of my classes: "Budget Rent-aCar" (for a complete transcription, see the section "Text and Exercises" below). The text was part of a larger thematic grouping on transportation that included plane travel, trains, taxis, and cycling. In order to situate the exercise for the reader, I'll provide a short description of the student population with whom the texts were used.

The first group of students ranged from 10-65 on our proficiency test, indicating they would be from the very elementary level to the mid-range of advanced according to the RSA listening levels. They were mostly adult students (20-40 years old) who wanted to learn English for professional and academic reasons. The group was multi-lingual and multi-cultural. The second group consisted of 16 Arabic-speaking students from the same country of origin. The overall range was similar to that in the first group. These students were learning English for professional purposes.

Within both groups, it was possible to identify three mini-groups having different levels of proficiency. In each case, the students were taught together for $80 \%$ of their program. Part of this time together was spent in the language lab. It was for these classes that the following exercises were prepared.

\section{Text and Exercises}

Students may be asked to do all or only a selection of the exercises. As the teacher gets to know the class better, exercises can be chosen to fit the needs of different groups.

For the very weak student, I would begin with a modified cloze exercise. In such an exercise, one can focus on many different aspects; i.e., the prices charged, the distances, lexical items, the destinations, the legal and 
health concerns, etc. This is illustrated in the following text (words in italics correspond to the deleted information):

\section{CLOZE EXERCISE: BUDGET RENT-A-CAR}

- Budget Rent-A-Car. May I help you?

- Yes, I would like information about a couple of things. First, how much does it cost to rent a small car on a daily basis?

- O.K. They're $\$ 27.95$ per day.

- O.K. What does that include?

- Ah...It includes 250 kilometers free with excess distance charged at 10 cents a kilometer. You're fully insured but it’s $\$ 300$ deductible. It’s $\$ 400$ a day.

- O.K. And can one rent a car with an international driver's licence?

- Yes, no problem.

- There's no problem.

- Ya. Was it issued in Canada or somewhere else?

- Issued in a country outside of Canada.

- Ya. No problem.

- The second thing - how much? Do you have any special weekend rates?

- Ya, the same car is $\$ 54.95$ from Friday anytime till Monday noon. You get 700 kilometers free, excess distance 10 cents a kilometer.

- O.K. This summer I'm going to be travelling out West and I was also wondering how much it would cost if I wanted to rent it on a two-week basis or would it be just as cheap to rent it for a month at a flat rate.

- O.K. Every rate that we have has mileage cap.

- O.K.

- You can only get so many free and after that it's 10 cents a kilometer.

- You can't pay.

- There's no unlimited mileage rates, no.

- O.K. And how much would it like... if I were to rent it? Do you have special rates if you rent it for a week, two weeks or three weeks?

- O.K. The same for one week is $\$ 165.00$ per week with 1750 kilometers free. The monthly rate is 590 kilometers a month with 4000 kilometers free.

- O.K. And the same deductible and insurance applies?

- Ya, ya.

- O.K. Thanks very much.

- Bye now.

- Bye.

As specified in the RSA guidelines for aural comprehension, the objective at the elementary level is to provide well-developed support structures and to focus students on factual text-based questions. Slightly more demanding than the cloze exercise illustrated above would be an exercise 
involving short answer questions. In the following exercise further support is provided by the division of the text into sections:

\section{ELEMENTARY}

\section{SHORT ANSWER}

Section A: Rates, Kilometers and Insurance

1. What company did he call?

2. How much does it cost to rent a car for a day?

3. How many free kilometers do you get?

4. How much extra do you pay for each kilometer?

5. If you had an accident, how much would you have to pay?

Section B: International Driver's Licence

1. Can you drive in Canada with an international driver's licence? (Questions about country of origin at this level would be too difficult as the students would have to comprehend and process a lot to be able to answer).

Section C: Weekend, Weekly and Monthly Rates

1. How much is a small car for the weekend?

2. When can you get the car? When do you have to take it back?

3. Where will the man be travelling this summer?

4. For how long does he want to rent the car?

Short answer, true/false and multiple choice questions can be profitably used at all levels. For intermediate and advanced students, however, a greater emphasis would be placed on the ability to draw inferences and to deal with larger chunks of information. At the higher levels the "Budget Rent-a-Car" passage could be exploited as follows:

\section{INTERMEDIATE AND ADVANCED}

\section{SHORT ANSWER}

1. If you rented a car for a day and drove $500 \mathrm{kms}$, how much would you have to pay over the daily rate?

2. I have an international driver's licence issued in Canada. Can I rent a car?

3. Would you be able to keep the weekend special as long as the daily rental? Explain.

4. Under what conditions might renting by the month be more economical? Renting by the day?

5. Does the car company offer the same insurance on all its rentals? 


\section{TRUE/FALSE}

1. The man wants to rent an imported car.

2. The accident insurance on the car covers all expenses.

3. If we rent a car by the month, we have unlimited mileage.

4. The speaker wants to rent a car to travel from Ottawa to the West.

5. With the weekend special, we can use the car for the full three-day period.

\section{MULTIPLE CHOICE}

1. From the conversation we discover that Budget Rent-A-Car

(a) offers a flat monthly rate.

(b) has 100 -dollar deductible insurance on all cars.

(c) charges 10 cents a $\mathrm{km}$ for each $\mathrm{km}$ the car travels.

(d) has a free mileage limit on all its cars.

If two dialogues like the Budget Rent-A-Car one are recorded, it is then possible to make comparisons; for example:

1) From which company can you get a better deal on a (a) daily, (b) weekly, (c) monthly basis?

2) Under what conditions would you pay a flat rate? daily rate? Another possibility would be to make comparisons between different means of transportation.

\section{Transfer-of-Information Exercises}

Transfer-of-information exercises involve the transfer of information from one medium to another, e.g., spoken to graphic, or written, or physical action. As concerns the language lab, the stimulus (text) is in the aural medium and is transferred to some form of written medium such as a diagram or graph.

Even something as commonplace as the daily weather forecast can be cast in graph or chart form. The difficulty of the task will vary according to the language proficiency of the students. At elementary levels a chart such as the one in Figure 3 could be provided. 


\section{ELEMENTARY}

Maximum Minimum Forecast

TODAY

TOMORROW

NEXT DAY

High Low Outlook

Figure 3. Chart for recording weather forecast.

Elementary students would simply be expected to complete the chart with one word answers such as "sunny" or "showers" for forecast. (Alternatively, a multiple choice format could be used.) At the intermediate levels the information could still be written in point form but students would be expected to extract more details. Advanced students could be asked to manipulate the information in more complex tasks; for example:

1. Write a short summary of the forecast for the next few days.

2. You are planning a beach party. Given the forecast for the next three days, explain when you would choose to hold it.

3. Present the weather information in a graph and plot the highs and lows for the forecast period.

Other transfer-of-information exercises are also possible. For example, the students listen to recorded text about birth and death rates, then plot the information on a graph. Elementary students will receive the graph and merely transfer figures. Intermediate and advanced students would be asked to draw the graph and plot the information, then asked to make predictions based on the graph.

Plotting information on graphs, following directions, indicating location, drawing, labelling - the possibilities are almost endless. In each case, the design of the activity involves varying the amount of information given and the difficulty of the task to be performed.

\section{CONCLUSION}

The methodology and sample exercises discussed in this paper offer one possible approach to the multi-level classroom. The success of this 
approach can be attributed to the fact that students are able to work at their own level and rhythm on material that is both interesting and challenging. As well, this approach demonstrates the flexibility and the utility of the language lab for language teaching. If the technical problems can be eliminated, the language lab can be an ideal place to provide students with stimulating information in a relaxed atmosphere. The language lab can thus meet two of Krashen's criteria for fostering acquisition: comprehensible input and a low affective filter. There is then, to conclude, more to life in the language lab than mere structural exercises.

\section{REFERENCES}

Asher, J. Learning another language through actions: The complete teacher's guidebook. Los Gatos: Sky Oaks Productions, 1977.

Gary, J.O. Delayed oral practice in initial stages of language learning. In M. Burt, and M. Dulay (Eds.), On TESOL '75: New directions in second language and bilingual education. Washington: TESOL, 1975.

Krashen, S. Second language acquisition and second language learning. Oxford: Pergamon Press, 1981.

Krashen, S. Principles and practice in second language acquisition. Oxford: Pergamon Press, 1982.

Postorsky, J. Effects of delay in oral practice at the beginning of second language learning. Modern Language Journal, 1974, 58, 229-239.

Rivers, W. and Temperly, M. A practical guide to the teaching of English. London: Oxford University Press, 1978.

Royal Society of Arts. Communicative use of English as a foreign language. London: Royal Society of Arts, 1981.

\section{THE AUTHOR}

Robert Courchêne is an ESL teacher at the Centre for Second Language Learning, University of Ottawa. His research interests include listening comprehension (in particular at the beginning levels), the use of the language laboratory as a teaching instrument, and definitions of communicative competence. 
APPENDIX A

\section{Royal Society of Arts (RSA) Band Levels for Testing Aural Comprehension}

\begin{tabular}{|c|c|c|c|}
\hline & BASIC LEVEL & INTERMEDIATE & ADVANCED \\
\hline Size & $\begin{array}{l}\text { Needs to understand only the main point(s) of } \\
\text { short examples of the limited range of text types } \\
\text { specified at this level. A restricted amount of } \\
\text { detail may be extracted if attention is directed to } \\
\text { it in advance. }\end{array}$ & $\begin{array}{l}\text { Can follow the significant points of texts of the } \\
\text { range of types specified at this level. Detail may also } \\
\text { be extracted if attention is directed to it in advance. }\end{array}$ & $\begin{array}{l}\text { Can understand the totality of all text types } \\
\text { specified at this level. }\end{array}$ \\
\hline Complexity & $\begin{array}{l}\text { Does not need to follow the detail of text construz- } \\
\text { tion. Major and subsidiary points may not be } \\
\text { differentiated. }\end{array}$ & $\begin{array}{l}\text { Major and subsidiary points will generally be dis- } \\
\text { tinguished. The structure of the text will usually } \\
\text { be perceived, though questions on this should only } \\
\text { relate to explicit markers. }\end{array}$ & $\begin{array}{l}\text { Can cope with texts and sequences of texts con- } \\
\text { taining a number of najor and subsidiary points. } \\
\text { Can perceive the relationship between all of these } \\
\text { and overall structure of text(s) even when they } \\
\text { are not signalled explicitly. }\end{array}$ \\
\hline Range & $\begin{array}{l}\text { Can handle the range of text types and perform } \\
\text { most of the operations specified at this level. } \\
\text { Accents will probably cause confusion. }\end{array}$ & $\begin{array}{l}\text { Can handle the range of text types and perform } \\
\text { most of the operations specified at this level. } \\
\text { 'Light' accents can be understood. }\end{array}$ & $\begin{array}{l}\text { Can handie the range of text types and perform } \\
\text { all operations specified at this level. Major British } \\
\text { accents can be understood. }\end{array}$ \\
\hline Speed & $\begin{array}{l}\text { Normal rate of delivery may be processed only } \\
\text { crudely. Slower, more deliberate tempo can nor- } \\
\text { mally be followed more easily and with more } \\
\text { detailed comprehension. }\end{array}$ & $\begin{array}{l}\text { Normal rate of delivery can be processed, though } \\
\text { this imposes strain after a relatively short time. It } \\
\text { should be interspersed with slower, more deliberate } \\
\text { tempo or periods of 'rest' in the examination } \\
\text { context. }\end{array}$ & $\begin{array}{l}\text { No allowance need be made in rate of delivery } \\
\text { of texts. }\end{array}$ \\
\hline Flexibility & $\begin{array}{l}\text { Switches of topic within a text need not be detec. } \\
\text { ted. Sequences of different text types, speakers, } \\
\text { topics may tend to unsettle the candidate. Back- } \\
\text { ground 'noise' of any sort may be upsetting and } \\
\text { may hamper comprehension. }\end{array}$ & $\begin{array}{l}\text { Switches of topic within a text can be detected. } \\
\text { Candidates can cope with sequences of different } \\
\text { text types, speakers, topics as long as these are not } \\
\text { over-rapid. Background noise hinders comprehension } \\
\text { but texts can still be processed crudely. }\end{array}$ & $\begin{array}{l}\text { Switches of topic, rate of delivery, speaker, text } \\
\text { type can be detected and assimilated without } \\
\text { confusion. Background 'noise' acceptable to a } \\
\text { native speaker does not significantly hinder } \\
\text { comprehension. }\end{array}$ \\
\hline Independence & $\begin{array}{l}\text { May process text only very crudely at first exposure. } \\
\text { Normally needs to be directed towards those } \\
\text { elements on which questions will be set. Repetition } \\
\text { will narmally be allowed at this level. }\end{array}$ & $\begin{array}{l}\text { Will process text with some sophistication at first } \\
\text { exposure. Some post-listening questions may thus } \\
\text { be set. However, most questions will direct the } \\
\text { candidate towards specific elements of the text. } \\
\text { This may involve repetition. }\end{array}$ & $\begin{array}{l}\text { Will process texts to which attention is directed } \\
\text { fully (in terms of range of operations) on only } \\
\text { one exposure. Post-listening questions may thus } \\
\text { be set. May require repetition to process detail } \\
\text { to w'ich attention has not been specifically directed. }\end{array}$ \\
\hline
\end{tabular}



VOL. 1, NO. 1, JAN 1984. 